\title{
Nutrition Management of Acute Postliver Transplant Recipients
}

\author{
Neha Bakshi, Kalyani Singh \\ Department of Food and Nutrition, Lady Irwin College, University of Delhi, New Delhi, India
}

\section{Abstract}

\begin{abstract}
Aim: Acute post liver transplant (LT) phase is characterized by hypermetabolism and increased nutrient requirements. This study aimed to provide the cardinal data on nutrition progression in the management of acute post-LT patients. Methods: This exploratory study recruited 54 adult acute post-LT recipients. The information regarding patient stay, weight status, biochemical parameters, and route of feeding was gathered. Recipients' dietary and nutrient intake was computed by 24-h dietary recall method. Results: The data exhibited a significant trend of lower hemoglobin, platelet, and albumin levels and increased bilirubin (T), alanine aminotransferase, aspartate aminotransferase, and gamma-glutamyl transferase levels $(P<0.05)$. In acute post-LT patients, a significant decrease in weight status $(P<0.001 * *)$ was observed. The recipients' information on daily nutrition progression showed significantly lower intake of calorie, protein, fats, calcium $(P<0.05)$ and lower percentage adequacy of other nutrients as compared to the recommended guidelines. The energy and protein intake from the parenteral route of feeding significantly decreased and that of through oral route significantly increased $(P<0.05)$ from postoperative day (POD) 2 to POD 9 and POD 12. Conclusion: There are scant data on nutrition management in acute post-LT phase. The present study provides the framework for the formulation of continuous, patient-centric, aggressive nutrition management interventions for acute post-LT recipients.
\end{abstract}

Keywords: Acute postliver transplant, nutrient intake, nutrition management, nutrition monitoring

\section{INTRODUCTION}

In India, liver transplantation is a relatively new area; by May 2007, it has been reported that 318 LTs were performed. ${ }^{[1]}$ Liver transplant (LT) is the only treatment for patients with irreversible liver failure. The recipients' treatment can be majorly considered in two phases, namely pretransplant phase and posttransplant phase. The posttransplant phase is further divided into acute posttransplant phase (immediate phase after LT) and chronic posttransplant phase (long-term follow-up). ${ }^{[2]}$

Acute post-LT is the immediate phase after transplantation. In this phase, the patient stays for 2 to 6 weeks in the transplant unit. ${ }^{[3]}$ An uncomplicated intensive care unit (ICU) stay after LT depends on the transplanted graft function assessed by various parameters such as wakefulness, improvement of muscle power, stable respiratory effort, normal mentation, change in drain fluid from serosanguinous to ascites, better laboratory parameters, lesser dependence on fresh-frozen plasma, and improved biochemical profile. ${ }^{[4]}$

Acute post-LT phase is characterized by catabolism due to surgery and corticosteroid administration which are anti-inflammatory and immunosuppressive drugs. ${ }^{[3]}$

\begin{tabular}{|l|l|}
\hline \multicolumn{3}{c|}{ Access this article online } \\
\hline Quick Response Code: & Website: \\
& www.ijccm.org \\
\hline
\end{tabular}

Hypermetabolism in cirrhosis is associated with unfavorable outcome after LT $^{[5-7]}$ and seems to regress with the improvement of body composition. ${ }^{\left[{ }^{8,9]}\right.}$ In this phase, electrolyte alterations are common. Sodium loss can be through urine, nasogastric tube, bile T-tube, and abdominal drains. Serum potassium (K), phosphorus, and magnesium levels tend to deplete rapidly in the acute post-LT phase due to diuretic use and refeeding syndrome. ${ }^{[10]}$

Various studies have focused on nutrition assessment and malnutrition in pre-LT phase and its effect on various prognostic, nutritional, and clinical factors and the outcomes of the surgery. ${ }^{[11-17]}$ There are very few studies addressing the nutritional aspects of acute post-LT phase. After LT, there is altered metabolism as the protein catabolism increases because of higher nitrogen losses ${ }^{[18]}$ According to the European Society of Parenteral and Enteral Nutrition (ESPEN) guidelines, patients are recommended higher protein $/ \mathrm{kg}$ body weight

Address for correspondence: Dr. Neha Bakshi, Lady Irwin College, University of Delhi, Skiandra Road, New Delhi - 110 001, India. E-mail: nehabakshi.9@gmail.com

This is an open access journal, and articles are distributed under the terms of the Creative Commons Attribution-NonCommercial-ShareAlike 4.0 License, which allows others to remix, tweak, and build upon the work non-commercially, as long as appropriate credit is given and the new creations are licensed under the identical terms.

For reprints contact: reprints@medknow.com

How to cite this article: Bakshi N, Singh K. Nutrition management of acute postliver transplant recipients. Indian J Crit Care Med 2018;22:773-80. 
(1.3-2 $\mathrm{g} / \mathrm{kg}$ body weight/day); energy requirement is not much significantly $(120 \%-130 \%$ of basal energy expenditure $[\mathrm{BEE}]$ or resting energy expenditure) increased if there are no major complications. Recommendations for carbohydrates and fats are $50 \%-70 \%$ and $<30 \%$ of the energy, respectively. Calcium is recommended at a range of $800-1200 \mathrm{mg} /$ day and sodium $(\mathrm{Na})$ at $2-4 \mathrm{mg} /$ day. For other vitamins and minerals, it is suggested to use the Recommended Dietary Allowance (RDA) ${ }^{[19]}$

Nutritional assessment and intervention are challenging preoperatively because of difficulties such as ascites, altered biochemical parameters, nausea, gastrointestinal-related problems, and gustatory sensations. ${ }^{[20]}$ The postoperative period could be more conducive to nutritional support as the patients are under continuous medical and nutritional monitoring. The healthy graft should improve the various associated factors which affected nutritional support prior to transplant. Hence, postliver transplant patients should demonstrate improved tolerance to nutrition (fluid, salt, and protein) and should be able to achieve positive nitrogen balance and restore lean body mass. ${ }^{[20,21]}$ The objective of medical nutrition therapy in acute post-LT phase is to provide adequate nutrition for the replenishment of lost nutrients and to promote recipient recovery. ${ }^{[10]}$ It is quite challenging to meet the nutrient requirements in acute post-LT phase because of excessive nausea after the surgery, nonfunctional or slow gastrointestinal functioning, metabolic complications, and lower performance status. ${ }^{[2]}$ Hence, recipients should be properly and timely checked for all the issues related to nutrition condition of the patient, which is known as nutrition monitoring. ${ }^{[23,24]}$

Considering the lack of information on the nutrition delivery in acute-post-LT phase, the present research aimed to provide data on the progression of biochemical, nutritional, and dietary profile of recipients in acute post-LT phase.

\section{Methods}

The present study focused on the barely studied aspect, that is, nutrition in acute post-LT phase. During the study period, three hospitals undertaking LT in Delhi and National Capital Region participated in the study. The present exploratory study purposely recruited 54 LT recipients ( $\geq 18$ years) who were suffering from end-stage liver disease (ESLD) for $\geq 2$ years before LT. Ethical clearance was obtained from the Institutional Ethical Committee. The recipients were followed up from the pre-LT phase to acute post-LT phase till discharge. Patients below 18 years of age and suffering from acute liver disease were excluded from the study.

The recipients were nutritionally monitored and followed up during their hospital stay immediately after the LT till discharge. Information was gathered regarding patient profile (age, gender, nationality, etiology, Child-Turcotte-Pugh [CTP] score, and Model for End-Stage Liver Disease [MELD] scores from hospital records). The everyday weight of the recipient was taken by using a digital weighing balance. Weight status was followed from pre-LT phase and acute posttransplant phase till the patient got discharged. Furthermore, patients' biochemical parameters, route of feeding, and dietary and nutrient intake were monitored which were then compared with the ESPEN guidelines (2006). The data were obtained from hospital records and by interviewing recipients, doctor, nurse, and dietitian concerned.

In the acute posttransplant phase, data were collected from the recipients' records and daily patient visits till discharge. Information regarding patients' admission, ICU stay, discharge, and hospital stay was collected. After LT, the patients were recommended disease-specific diets through various routes of feeding so that patients could maintain intake according to the recommended requirements [Table 1]. This was attained with nutrition support from various routes of feeding, namely total parenteral nutrition, enteral, oral with or without nutritional supplements, and two or more combinations of routes of feeding. The amounts of calorie and protein intake from these routes were accounted.

Information regarding dietary intake was computed from 24-h dietary recall. In acute post-LT phase, till the patient got discharged from the hospital, daily calorie and protein intake of the patients was recorded. This information was gathered from the hospital records to provide the trend of calorie and protein consumption from various routes of feeding (enteral, parenteral, oral, and oral nutritional supplements). Since patents' stay in hospital varies according to medical condition, hence Post Operative Day (POD) 2, 9 and 12 were analyzed for uniform trend analysis.

Furthermore, 2-day detailed dietary recalls of the patients were computed on PODs 5 and 10 for a uniform analysis when the patients were having only oral route of feeding with diet or oral high calorie and protein supplements with or without combinations of other routes such as enteral/parenteral. These recalls were used to analyze the macro- and micro-nutrient intake of the patients. The data were analyzed using DietCal software(C) 2014 version 5.0 (Profound tech solutions, New Delhi, India).

Biochemical tests were required to assess the nutritional status of LT patients. The information was collected as secondary data from the hospital records and patient reports. These parameters were checked daily for any alterations. Various biochemical parameters such as hemoglobin, white blood cells, platelets, and liver function tests were monitored throughout the patient stay in acute post-LT phase. To get the trend of the biochemical profile of patients, their levels were followed up from pretransplant stage to postoperative stage, until discharge. Patients after the surgery get discharged on the basis of their medical condition; therefore, the hospital stay varies for each patient. Hence, the biochemical data till POD 12 were used so that there are sufficient and continuous data for analysis.

All statistical analyses were performed using the Statistical Package for the Social Sciences (SPSS) version 17.0 for Windows (SPSS Inc., Chicago, IL, USA). Continuous variables 


\begin{tabular}{lc}
\hline Table 1: Recipients' profile & \multicolumn{1}{c}{ Result } \\
\hline Clinical parameter & $48.6 \pm 10.2$ \\
\hline Age years (mean \pm SD) & $39(72.2) / 15(27.8)$ \\
Gender, $n(\%)($ male/female) & $33(61.1) / 18(33.3) / 3(5.5)$ \\
Nationality, $n(\%)($ Indian/Pakistani/Uzbeks) & $1(1.9) / 20(37.0) / 33(61.1)$ \\
CTP Grade, $n(\%)(\mathrm{A} / \mathrm{B} / \mathrm{C})$ & $4(7.4) / 28(51.9) / 22(40.7)$ \\
MELD scores (>24/19-24/<19) & $26(48.1) / 12(22.2) / 6(11.1) / 10(18.5)$ \\
Etiology, $n(\%)($ viral/alcoholic/cryptogenic/others) & $30 / 23 / 38$ \\
Maximum number of days patients were in: ICU/ventilator/total hospital stay & \\
\hline
\end{tabular}

Route of feeding $(n=54)$

\begin{tabular}{lc}
\hline Oral,$n(\%)(\mathrm{POD}-3 / 6 / 9)$ & $27(50) / 52(96.2) / 51(94.4)$ \\
$\mathrm{NPO}, n(\%)(\mathrm{POD}-3 / 6 / 9)$ & $18(33.3) / 0(0) / 1(1.8)$ \\
Enteral, $n(\%)(\mathrm{POD}-3 / 6 / 9)$ & $0(0) / 2(3.7) / 1(1.8)$ \\
Parenteral, $n(\%)(\mathrm{POD}-3 / 6 / 9)$ & $5(9.2) / 0(0) / 1(1.8)$ \\
NPO + parenteral, $n(\%)(\mathrm{POD}-3 / 6 / 9)$ & $4(7.4) / 0(0) / 0(0)$ \\
\hline
\end{tabular}

\begin{tabular}{|c|c|}
\hline \multicolumn{2}{|c|}{ Type of diet $(n=54)$} \\
\hline Normal, $n(\%)(\mathrm{POD}-3 / 6 / 9)$ & $0(0) / 7(12.9) / 33(61.1)$ \\
\hline Soft, $n(\%)($ POD - 3/6/9) & $1(1.9) / 38(70.3) / 17(31.4)$ \\
\hline Liquid, $n(\%)(\mathrm{POD}-3 / 6 / 9)$ & $19(35.1) / 2(3.7) / 1(1.9)$ \\
\hline Clear liquid, $n(\%)(\mathrm{POD}-3 / 6 / 9)$ & $7(12.9) / 3(5.5) / 0(0)$ \\
\hline $\mathrm{NPO}, n(\%)(\mathrm{POD}-3 / 6 / 9)$ & $27(50) / 4(7.4) / 3(5.5)$ \\
\hline
\end{tabular}

$n$ : Number of patients; SD: Standard deviation; POD: Postoperative day; CLD: Chronic liver disease; HBV: Hepatitis B virus; HCV: Hepatitis C virus; CTP: Child-Turcotte -Pugh, MELD, Model for End-Stage Liver Disease; HCC: Hepatocellular carcinoma; NPO: Nil per oral; ICU: Intensive care unit

were presented as mean \pm standard deviation (SD) and categorical variables were presented as absolute numbers and percentage. Data were checked for normality before statistical analysis. Nonnormally distributed continuous variables were compared using Mann-Whitney U-test for two-group comparisons and Kruskal-Wallis test was used to compare the three groups. Trend analysis of biochemical parameters and calorie and protein intake from the different routes of feeding over a period of time was performed by repeated analysis of variance (ANOVA) measures.

\section{RESULTS}

The demographic and clinical data of 54 LT recipients are presented in Table 1. Before the LT, $61.1 \%$ of the patients were in CTP Grade C and $51.9 \%$ of the patients in the MELD range of 19-24, which affirms the disease severity. Diagnostically, $48.1 \%$ and $22.2 \%$ of the patients were undergoing LT because of viral infections and ethanol-related CLD, respectively. The total hospital stay of the recipients was a maximum of 38 days and a minimum of 11 days. The maximum number of days recipients were on ventilator and ICU was 23 and 30 days, respectively. During the patient stay, they were recommended different types of diets through various routes of feeding according to their ability to eat and tolerate food. Table 1 shows that $50 \%$ of the patients were having an oral route of feeding and $9.2 \%$ of the patients were having parenteral route of feeding by POD 3. By POD 6, 96.2\% of the patients were having oral diet and only $3.7 \%$ were on an enteral diet. The data on the type of diet showed that by POD 3, 50\% of the patients were nil per oral (NPO) and $35.1 \%$ were on a liquid diet; $61.1 \%$ of the patients were having normal diet and $70.3 \%$ of the patients were on a liquid diet by POD 9. These data exhibited progression of the route of feeding and type of diet in acute post-LT phase [Table 1].

None of the previous studies have focused on drawing a trend of these biochemical parameters, which can form baseline data for future medical and nutritional interventions in acute post-LT phase. The trend analysis represented a significant decrease of hemoglobin levels over a period of time from pretransplant phase till acute post-LT phase, as compared to the gender-specific cutoffs [Figure 1] $(F=6.471, P<0.001)$. Majority of the patients were male and a small number $(n=15)$ were female; a separate trend analysis for females would not provide any concrete analysis. Platelet levels depicted a statistically significant $(P=0.03)$ increase from pretransplant to acute posttransplant phase which became normal by POD 12 . The albumin levels after POD 3 showed a constant and statistically significant $(F=4.622, P=0.001)$ rise, but were still below the normal level [Figure 1]. In the present study, no significant trend was observed in bilirubin (D) levels, but bilirubin (T) levels showed a statistically significant $(F=11.027$, $P=0.001$ ) decreasing trend [Figure 1]. Figure 2 shows that after POD 2, alanine aminotransferase (ALT) and aspartate aminotransferase (AST) levels showed a significant decreasing trend, but were still higher than the normal level $(P=0.023)$ till POD 12 in LT recipients. $\gamma$-glutamyl transferase $(\gamma-G T)$ showed significantly decreased levels after POD 2 which came down to normal levels after POD $5(P<0.001)$. The trend analysis on alkaline phosphatase depicts significant normal levels of alkaline phosphate till POD $10(P<0.001)$. In the present study, the levels of Na showed a statistically significant difference $\left(P<0.001^{* *}\right)$ over a period of time. After LT, the 
levels of $\mathrm{Na}$ were in the normal range till POD 5; after that, it gradually decreased till POD 12 [Figure 2]. The mean K levels over a period of time showed a significant increasing and decreasing trend $\left(P<0.001^{* *}\right)$ but within the normal range [Figure 1]. In acute post-LT patients, alteration in any of the above biochemical parameters will modify the nutrition interventional plan for the holistic well-being of patients.

The weight status of patients over a period of time also showed a significant difference from pre-LT phase till acute post-LT phase. The data represent a significantly decreasing trend of weight status [Table 2] .

The study provided less explored aspect in the treatment of acute liver transplant patients, that is, nutrient and dietary intake. The dietary behavior of the patients was determined by computing the mean food intake of the acute postliver transplant recipients. The sample was divided according to the country of origin (India, Pakistan, and Uzbekistan). The mean food intake with SD is presented in Table 3 as there are no specific guidelines for LT patients in terms of food groups and exchanges for comparison. The patients' intake was divided in terms of food groups which can assist in planning nutrition intervention with a focus on nutrient-specific foods. The data

\begin{tabular}{|c|c|c|c|c|}
\hline & Mean $(\mathrm{Kg})$ & SD & $n$ & $P$ \\
\hline Pre-LT & 71.2750 & 10.00222 & 40 & $<0.001 * *$ \\
\hline POD 2 & 71.0400 & 9.87166 & 40 & \\
\hline POD 3 & 70.5225 & 9.83402 & 40 & \\
\hline POD 4 & 70.2675 & 10.00526 & 40 & \\
\hline POD 5 & 69.9600 & 10.01757 & 40 & \\
\hline POD 6 & 69.6350 & 9.98457 & 40 & \\
\hline POD 7 & 69.5250 & 10.02448 & 40 & \\
\hline POD 8 & 69.5275 & 10.09681 & 40 & \\
\hline POD 9 & 69.5300 & 10.24305 & 40 & \\
\hline POD 10 & 69.5625 & 10.26759 & 40 & \\
\hline POD 11 & 69.4475 & 10.31919 & 40 & \\
\hline POD 12 & 69.4675 & 10.45779 & 40 & \\
\hline POD 13 & 69.4150 & 10.79541 & 40 & \\
\hline
\end{tabular}

$n$ : Number of patients; POD: Postoperative day; SD: Standard deviation; **Highly significant values

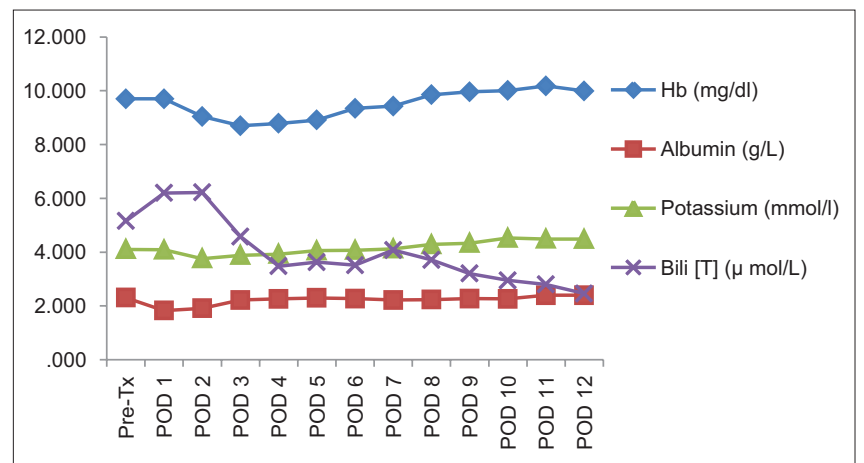

Figure 1: Trend analysis of biochemical parameters-I. mg/dl: Milligram/deciliter; g/L: Gram/liter; mmol/L: Millimol/liter; $\mu \mathrm{mol} / \mathrm{l}$ : Micromol/liter; Pre-Tx: Pretransplant; POD: Postoperative day showed food group intake as per the percentage calorie and protein intake. The percentage calorie and protein intake was majorly from cereals and milk and milk products with a minimal intake of fruits and vegetables. The study provides the only information on dietary intake of the patients in acute post-LT phase.

In the acute posttransplant phase, patients' intake was compared with the recommendations given by the ESPEN 2006 and $\mathrm{RDA}^{[2,19,25-27]}$ for liver disease and LT. The BEE ${ }^{[2]}$ was translated to the energy requirement for the acute post-LT patients. A 2-day detailed 24-h dietary recall was performed for PODs 5 and 10.

The data analyzed the nutrient intake with recommendations which represented that patients' calorie intake and protein intake were significantly lower than that of the ESPEN guidelines. It also showed significantly lower total fat and calcium intake than that of the ESPEN recommendations. The dietary Na intake of the patients was $301 \mathrm{mg}$; comparison with guidelines could not be made as it was difficult to determine the $\mathrm{Na}$ intake from both diet and salt among the patients [Table 4].

Intake of other nutrients by patients is represented as means and compared with RDA. The ESPEN 2006 guidelines ${ }^{[2,19]}$ recommended the use of RDA to determine the requirements of nutrients other than energy, protein, fats, calcium, and $\mathrm{Na}$ in acute-post-LT phase. The RDA was available for Indian ${ }^{[25]}$ and Pakistani patients. ${ }^{[26]}$

The data in Figure 3 show the percentage nutrient adequacy of Indian patients. Only phosphorus was having nutrient adequacy $>100 \%$ in both men and women. Thiamine, riboflavin, Vitamin C, and Vitamin B12 are the nutrients with $>50 \%$ of adequacy according to the Indian RDA. Other nutrients such as iron, $\beta$-carotene, folic acid, Vitamin $A$, magnesium, and zinc were having lower percentage adequacy $(<50 \%)$. For Pakistani patients, RDA values for iron, Vitamin A, and zinc ${ }^{[26]}$ were available and compared to the intake of acute post-LT patients. Figure 4 shows that iron and zinc consumption was $<50 \%$, whereas that of Vitamin A was $53.9 \%$ of the RDA.

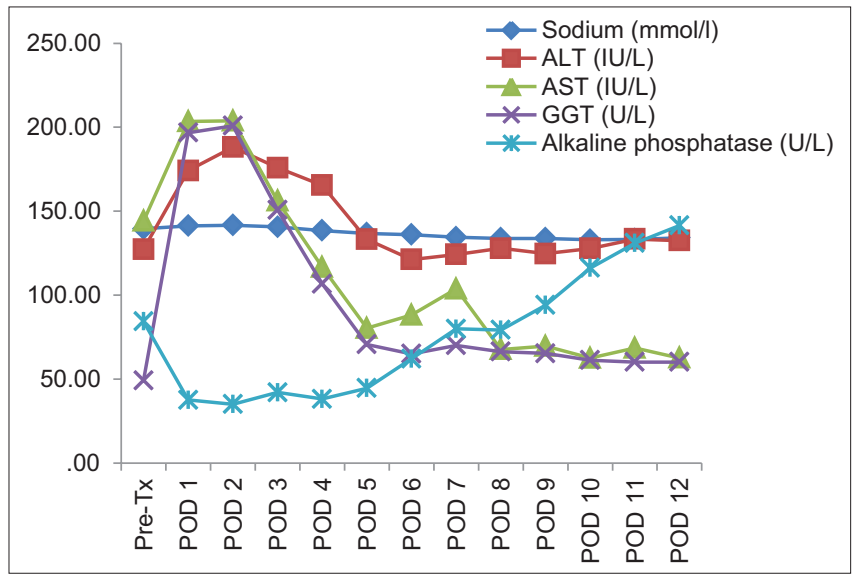

Figure 2: Trend analysis of biochemical parameters-II. mmol/L: Millimol/liter; IU/L: International unit/liter; Pre-Tx: Pretransplant; POD: Postoperative day 


\begin{tabular}{lccccc}
\hline \multicolumn{4}{l}{ Table 3: Patients food group intake in acute postliver transplant phase in percentage calorie and protein intake } \\
\hline Food groups (g) & Mean (g) & Energy (Kcal) & Percentage calorie intake & Protein (g) & Percentage protein intake \\
\hline Cereal grains and products & $182.2 \pm 80.9$ & $626 \pm 293.6$ & 41.6 & $17.8 \pm 8.3$ & 20 \\
Pulses and legumes & $48.3 \pm 63.4$ & $160 \pm 211$ & 10.6 & $11.1 \pm 14.7$ & $38.9 \pm 41.4$ \\
Meat and poultry & $168.3 \pm 177.6$ & $195 \pm 207$ & 12.9 & $19.1 \pm 7.3$ & 0 \\
Milk and milk products & $605.4 \pm 224.4$ & $360 \pm 139$ & 23.9 & $1.7 \pm 2.0$ & 0 \\
Leafy vegetables & $1.1 \pm 8.2$ & $0 \pm 2$ & 2.3 & 0 & 0 \\
Other vegetables & $88.4 \pm 101.6$ & $35 \pm 41$ & 0.1 & 0 & 0 \\
Roots and tubers & $4.8 \pm 15.8$ & $2 \pm 7$ & 0.7 & 0 & 0 \\
Fruits & $10.8 \pm 42.5$ & $12 \pm 24$ & 5.8 & 0 & 0 \\
Fats and edible oils & $9.3 \pm 10.9$ & $88 \pm 98$ & 1.5 & 0 \\
Sugars & $6 \pm 4.6$ & $24 \pm 18$ & & 0 \\
\hline
\end{tabular}

$n$ : Number of patients; SD: Standard deviation

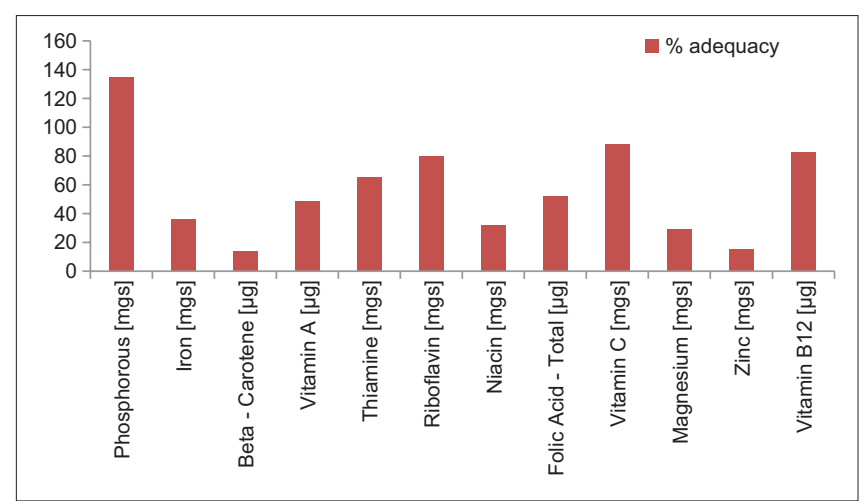

Figure 3: \% adequacy of nutrients for Indian patients (acute post-LT). \%: Percent; LT: Liver transplant; mgs: Milligrams; $\mu \mathrm{g}$ : Microgram

The study also aimed to provide the trend of energy and protein intake among acute post-LT recipients. During this phase, the patients were followed up every day for dietary calorie and protein intake through various routes of feeding. Since patients' stay in hospital varies according to their medical conditions, for a uniform trend of energy intake through different routes of feeding, intake from PODs 2, 9, and 12 was analyzed by ANOVA with a significance level of $P<0.05$ [Table 5].

The present study shows a trend of calorie and protein intake in Table 5 through parenteral route depicting a significant decrease of parenteral calorie and protein intake over a period of time from PODs 2, 9, and $12\left(P<0.001\right.$ and $\left.P=0.014^{*}\right)$, but there was no difference from PODs 9 and 12. There were no significant differences in the calorie and protein intake through enteral route from PODs 2, 9, and 12. The data in Table 5 show that patients with oral routes of feeding and with oral supplementation had significantly higher calorie and protein intake over a period of time (PODs 2,9 , and 12) $(P<0.05)$.

\section{Discussion}

Acute post-LT is the immediate phase after LT surgery. It is characterized by catabolism due to surgery and corticosteroid administration. ${ }^{[3]}$ Previous studies have already shown the level of nutrition status and impact of malnutrition on various factors for the holistic well-being of LT recipients in the pre-LT phase. ${ }^{[14,29]}$

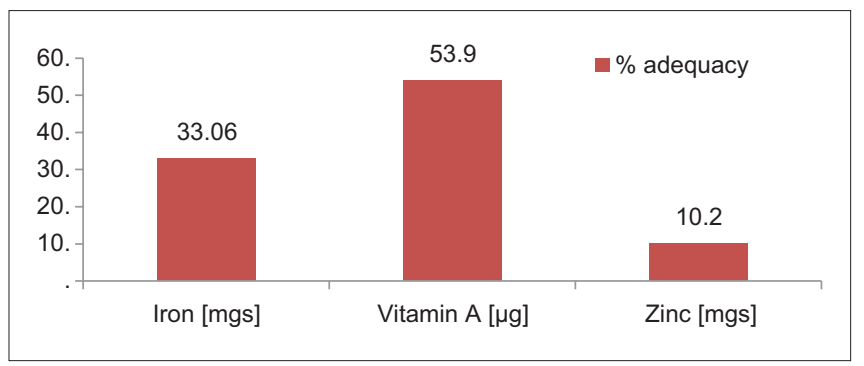

Figure 4: \% adequacy of nutrients for Pakistani patients (acute post-LT). \%: Percent; LT: Liver transplant; mgs: Milligrams; $\mu \mathrm{g}$ : Microgram

The present study provides the only data on dietary and nutrition progression in acute post-LT phase. The nutrition treatment of acute-LT patients lacks proper nutrition guidelines, though the ESPEN, 1997 and 2006,,$^{[2,19,27]}$ has recommended guidelines for LT recipients. The ESPEN recommends exclusive guideline for nutrition therapy during the entire acute posttransplant phase without exception. However, the patients have varied hospital stay as shown in Table 1, with a minimum of 11 days and a maximum of 38 days. It was apparent that the patients after LT stay for ample amount of time in hospital which could be considered as a conducive period for nutrition intervention and management. ${ }^{[21]}$

Regular biochemical analysis helps in screening for liver infections, monitoring the progression of the disease and determining treatment, measuring the severity of the disease, and monitoring possible side effects of medications. The data in Figures 1 and 2 show the altered biochemical profile of the recipients, which define further medical and nutrition treatment. The data showed a significant trend of improving hemoglobin, platelets, albumin, bilirubin (T), ALT, AST, $\gamma$-GT, alkaline phosphatase, $\mathrm{Na}$, and $\mathrm{K}$ levels. These trends gave the necessary information about the alterations in biochemical parameters which formulate the substructure for exclusive nutrition intervention during the acute post-LT phase. Although the biochemical levels were improving after the LT, there were lower hemoglobin, platelets, albumin, and $\mathrm{Na}$ levels and higher bilirubin (T), ALT, AST, $\gamma$-GT, and alkaline phosphatase levels, which warranted day-to-day change in nutrition therapy plan during the acute post-LT phase. Previous case reports on nutrition progression also showed an altered biochemical 
profile of LT recipient in acute post-LT phase, which directly affected the patients' nutrient intake. ${ }^{[30,31]}$

In the present study during the hospital stay, each day, patients were weighed if they were in a position to stand from pretransplant stage till acute posttransplant stage. Although weight alone is not an important indicator of patients' nutrition status, continuous monitoring of the weight provided the trend of weight gain or loss over a period of time. The data represent a significantly decreasing trend of weight status [Table 2]. During the acute post-LT phase, patients suffer from hypermetabolism, surgery stress, excessive nausea, pain, lack of appetite, and regular tests requiring blood withdrawal or NPO, which could be the possible reasons for weight loss. ${ }^{[16,19]}$

The dietary data of various food groups showed the mean intake of recipients as it would not be appropriate to compare normal individual recommendations with acute post-LT recipients because their requirements are different. The data also explored the percentage energy and protein intake as per the food groups, which showed the lower contribution

\begin{tabular}{|c|c|c|c|}
\hline \multirow[t]{2}{*}{ Intake } & \multicolumn{2}{|c|}{ Mean \pm SD } & \multirow[t]{2}{*}{$P$} \\
\hline & $\begin{array}{l}\text { Intake } \\
(n=54)\end{array}$ & $\begin{array}{l}\text { Recommended by } \\
\text { the ESPEN }(n=54)\end{array}$ & \\
\hline Energy day 1 (kcal) & $1038 \pm 492$ & $3347 \pm 409$ & $<0.001^{* *}$ \\
\hline Protein day 1 (g) & $52.9 \pm 25.3$ & $110 \pm 14.1$ & $<0.001 * *$ \\
\hline Energy day 2 (kcal) & $1245 \pm 509$ & $3347 \pm 409$ & $<0.001 * *$ \\
\hline Protein day 2 (g) & $67.1 \pm 29.2$ & $110 \pm 14.1$ & $<0.001 * *$ \\
\hline Fat $(\mathrm{g})$ & $35.7 \pm 18.0$ & $111.5 \pm 13.5$ & $<0.001 * *$ \\
\hline Calcium (mg) & $701.1 \pm 273.3$ & $1000 \pm 0.0$ & $<0.001 * *$ \\
\hline
\end{tabular}

$n$ : Number of patients; SD: Standard deviation; ESPEN: European Society of Parenteral and Enteral Nutrition; **Highly significant values of milk and its products, fruits, and vegetables in percentage energy and protein intake of the recipients [Table 3]. Factors such as nausea, hospital food, and functional inability make it difficult for patients to consume adequate quantities of food. ${ }^{[9,19]}$ Hence, the data emphasize the need for more specialized food group-oriented nutrition guidelines for devising a commodious nutrition intervention in LT recipients.

The data represented in Table 4 show that patients' calories, protein, fat, and calcium intake was significantly lower $(P<0.05)$ than that of the ESPEN 2006 guidelines. Furthermore, Figures 3 and 4 show lower percentage adequacy of other nutrients. This emphasizes the need for continuous aggressive nutrition intervention for these patients. However, it is challenging to maintain adequate nutrient intake after the surgery. Early posttransplant nutritional therapy seems to improve a number of surrogates parameters of nutritional status in recipients, but clear evidence for an improvement of posttransplant outcome is lacking. ${ }^{[32,33]}$ Hence, the data provide the baseline to establish nutrition intervention in acute post-LT recipients.

The patients' ability to consume the diet is defined by their route of feeding with a focus on small frequent meals. ${ }^{[19]}$ In acute post-LT phase, the recommendations for nutrients are quite high because of the focus on quick patient recovery and for early graft growth in the recipients. To meet such high nutrient requirements, different routes of feeding are used. Patients should progress from nutrition support to oral diets as soon as possible after LT. Due to medicational side effects, early satiety and taste changes are common complaints of patients. Small, frequent feedings of high-protein foods help patients achieve adequate nutrient requirements. Tube feeding can be administered on a cyclic or nocturnal schedule. Tube feeding should not be discontinued until patients are capable of eating two-thirds to three-fourths of their estimated nutrient requirements consistently. ${ }^{[16,34-36]}$

Table 5: Calorie and protein intake through different routes of feeding

\begin{tabular}{|c|c|c|c|c|c|c|c|c|c|c|c|}
\hline \multicolumn{7}{|c|}{ Calorie intake through different routes of feeding } & \multicolumn{5}{|c|}{ Protein intake through different routes of feeding } \\
\hline $\begin{array}{l}\text { Route of } \\
\text { feeding }\end{array}$ & POD & $\begin{array}{c}\text { Calorie } \\
\text { intake (kcal) } \\
\text { mean } \pm \text { SD }\end{array}$ & $P$ & $\begin{array}{c}P 2^{\text {nd }} \\
\text { day- } \\
9^{\text {th }} \text { day }\end{array}$ & $\begin{array}{c}P 2^{\text {nd }} \\
\text { day- } \\
12^{\text {th }} \text { day }\end{array}$ & $\begin{array}{c}P g^{\text {th }} \\
\text { day- } \\
12^{\text {th }} \text { day }\end{array}$ & $\begin{array}{c}\text { Protein } \\
\text { intake }(g) \\
\text { mean } \pm \text { SD }\end{array}$ & $P$ & $\begin{array}{c}P 2^{\text {nd }} \\
\text { day- } \\
9^{\text {th }} \text { day }\end{array}$ & $\begin{array}{c}P 2^{\text {nd }} \\
\text { day- } \\
12^{\text {th }} \text { day }\end{array}$ & $\begin{array}{c}P 9^{\text {th }} \\
\text { day- } \\
12^{\text {th }} \text { day }\end{array}$ \\
\hline \multirow{3}{*}{$\begin{array}{l}\text { Parental } \\
\text { route }\end{array}$} & $2^{\text {nd }}$ & $165 \pm 177$ & $<0.001 * *$ & $<0.001 * *$ & $<0.001 * *$ & 0.074 & $0.2 \pm 0.6$ & $0.014^{*}$ & 0.375 & 0.098 & 0.180 \\
\hline & $9^{\text {th }}$ & $64 \pm 189$ & & & & & $1.1 \pm 6.0$ & & & & \\
\hline & $12^{\text {th }}$ & $26 \pm 79$ & & & & & $0.2 \pm 1.6$ & & & & \\
\hline \multirow[t]{3}{*}{ Oral route } & $2^{\text {nd }}$ & $31 \pm 87$ & $<0.001 * *$ & $<0.001 * *$ & $<0.001 * *$ & $0.040^{*}$ & $0.4 \pm 1.3$ & $<0.001 * *$ & $<0.001 * *$ & $<0.001 * *$ & 0.058 \\
\hline & $9^{\text {th }}$ & $1044 \pm 588$ & & & & & $48.8 \pm 27.6$ & & & & \\
\hline & $12^{\text {th }}$ & $1196 \pm 630$ & & & & & $54.2 \pm 29.9$ & & & & \\
\hline \multirow{3}{*}{$\begin{array}{l}\text { Oral } \\
\text { supplements }\end{array}$} & $2^{\text {nd }}$ & $8 \pm 30$ & $<0.001 * *$ & $<0.001 * *$ & $<0.001 * *$ & $0.009 * *$ & $0.9 \pm 3.5$ & $<0.001 * *$ & $<0.001 * *$ & $<0.001 * *$ & $0.011 *$ \\
\hline & $9^{\text {th }}$ & $128 \pm 161$ & & & & & $11.6 \pm 12.6$ & & & & \\
\hline & $12^{\text {th }}$ & $201 \pm 216$ & & & & & $16.4 \pm 16.6$ & & & & \\
\hline \multirow[t]{3}{*}{ Total } & $2^{\text {nd }}$ & $204 \pm 171$ & $<0.001 * *$ & $<0.001 * *$ & $<0.001 * *$ & $0.019^{*}$ & $1.6 \pm 3.7$ & $<0.001 * *$ & $<0.001 * *$ & $<0.001 * *$ & $0.014 *$ \\
\hline & $9^{\text {th }}$ & $1285 \pm 594$ & & & & & $63.5 \pm 31.7$ & & & & \\
\hline & $12^{\text {th }}$ & $1485 \pm 732$ & & & & & $73.6 \pm 36.1$ & & & & \\
\hline
\end{tabular}

$n$ : Number of patients; POD, Postoperative day; SD: Standard deviation; *Significant, ** Highly significant 
Patients are continuously monitored in this phase to analyze the intake of energy and protein from different routes of feeding. The data in Table 5 clearly show a significant increase in oral calorie and protein intake from diet and oral supplementation from PODs 2 to 9 and 12. It also depicted that calorie and protein intake significantly decreased in the parenteral route of feeding $(P<0.05)$. Various previous studies have focused on the need for nutrition intervention in LT recipients because of the high prevalence of malnutrition and nutrition-related complication (hypermetabolism, gastrointestinal symptoms, etc.) before and after the LT. ${ }^{[2,10,11]}$ The present study attempted to record these much-needed data on nutrition requirements and nutrition progression. The study could include only 54 LT patients. Higher sample size would have presented more generalized data.

Hence, the present data provided the baseline information about the diet progression among acute post-LT patients. Although the present study has limitations of small sample size and there is a need for larger prospective studies on nutrition progression in acute post-LT, these data can lay the foundation for further nutrition intervention directing the medical nutrition therapy among acute post-LT patients. Thus, it emphasizes the need for continuous, patient-centric, aggressive nutrition support in the acute post-LT recipients.

\section{Conclusion}

This particular study provided information on the least studied aspect, that is, the trend of the altered biochemical profile, lower nutrient intake, and route of feeding, which formulates the backbone of nutrition management in acute post-LT patients. Furthermore, the data emphasized the need for more specialized nutrition and dietary guidelines for LT recipients.

\section{Acknowledgment}

The authors are thankful to Dr. A.S. Soin (Chief Hepatobiliary and Liver Transplant Surgeon and Chairman of Medanta Institute of Liver Transplantation and Regenerative Medicine, Medanta - The Medicity, Gurgaon, India), Dr. Subash Gupta (Chief Liver Transplant/Hepatobiliary Surgeon and Director, CLBS, Indraprastha Apollo Hospital, New Delhi, India), and Dr. Vivek Vij (Director, Liver Transplant, and Gastrointestinal surgery Fortis Hospital, Noida) for permitting the author to collect information regarding liver transplant patients from their institute.

\section{Financial support and sponsorship}

Nil.

\section{Conflicts of interest}

There are no conflicts of interest.

\section{References}

1. Kumaran V. Liver Transplantation in India. Textbook of Surgical Gastroenterology. $1^{\text {st }}$ ed. New Delhi: The Health Sciences Publisher; 2016. p. 1172
2. Plauth M, Cabré E, Riggio O, Assis-Camilo M, Pirlich M, Kondrup J, et al. ESPEN guidelines on enteral nutrition: Liver disease. Clin Nutr 2006;25:285-94.

3. Heymsfield SB, Waki M, Reinus J. Are patients with chronic liver disease hypermetabolic? Hepatology 1990;11:502-5.

4. Gopal PB, Kapoor D, Raya R, Subrahmanyam M, Juneja D, Sukanya B. Critical care issues in adult liver transplantation. Indian J Crit Care Med 2009;13:113-9.

5. Mathur S, Peng S, Gane EJ, McCall JL, Plank LD. Hypermetabolism predicts reduced transplant-free survival independent of MELD and Child-Pugh scores in liver cirrhosis. Nutrition 2007;23:398-403.

6. Müller MJ, Böker KH, Selberg O. Are patients with liver cirrhosis hypermetabolic? Clin Nutr 1994;13:131-44.

7. Selberg O, Böttcher J, Tusch G, Pichlmayr R, Henkel E, Müller MJ. Identification of high- and low-risk patients before liver transplantation: A prospective cohort study of nutritional and metabolic parameters in 150 patients. Hepatology 1997;25:652-7.

8. Plank LD, Metzger DJ, McCall JL, Barclay KL, Gane EJ, Streat SJ, et al. Sequential changes in the metabolic response to orthotopic liver transplantation during the first year after surgery. Ann Surg 2001;234:245-55.

9. Plauth M, Schütz T, Buckendahl DP, Kreymann G, Pirlich M, Grüngreiff $\mathrm{S}$, et al. Weight gain after transjugular intrahepatic portosystemic shunt is associated with improvement in body composition in malnourished patients with cirrhosis and hypermetabolism. J Hepatol 2004;40:228-33.

10. Campos AC, Matias JE, Coelho JC. Nutritional aspects of liver transplantation. Curr Opin Clin Nutr Metab Care 2002;5:297-307.

11. Bakshi N, Singh K. Nutrition assessment in patients undergoing liver transplant. Indian J Crit Care Med 2014;18:672-81.

12. Mohanka R, Yadav SK, Bakshi N, Saraf N, Balachandran P, Saigal S, et al. Nutrition Status Using Subjective Global Assessment (SGA) independently predicts outcome of patients waiting for living donor liver transplant. Liver Transplant 2014;20:353-4.

13. Bakshi N, Singh K. Effect of malnutrition on health-related quality of life (HRQoL) of patients awaiting liver transplantation. Indian J Transplant 2015;9:61-4.

14. Bakshi N, Singh K. Nutrition assessment and its effect on various clinical variables among patients undergoing liver transplant. Hepatobiliary Surg Nutr 2016;5:358-71.

15. Bakshi N, Singh K, Soin AS. Effect of pre-transplant malnutrition on outcomes of liver transplantation. J Clin Exp Hepatol 2016;6:S60.

16. Hasse JM, Blue LS, Crippin JS, Goldstein RM, Jennings LW, Gonwa TA, et al. The effect of nutritional status on length of stay \& clinical outcomes following liver transplantation. J Am Dietetic Assoc 1994;94:A38.

17. Pikul J, Sharpe MD, Lowndes R, Ghent CN. Degree of preoperative malnutrition is predictive of postoperative morbidity and mortality in liver transplant recipients. Transplantation 1994;57:469-72.

18. Shanbhogue RL, Bistrian BR, Jenkins RL, Randall S, Blackburn GL. Increased protein catabolism without hypermetabolism after human orthotopic liver transplantation. Surgery 1987;101:146-9.

19. Weimann A, Braga M, Harsanyi L, Laviano A, Ljungqvist O, Soeters P, et al. ESPEN guidelines on enteral nutrition: Surgery including organ transplantation. Clin Nutr 2006;25:224-44.

20. Porayko MK, DiCecco S, O'Keefe SJ. Impact of malnutrition and its therapy on liver transplantation. Semin Liver Dis 1991;11:305-14.

21. Reilly J, Mehta R, Teperman L, Cemaj S, Tzakis A, Yanaga K, et al. Nutritional support after liver transplantation: A randomized prospective study. JPEN J Parenter Enteral Nutr 1990;14:386-91.

22. Sanchez AJ, Aranda-Michel J. Nutrition for the liver transplant patient. Liver Transpl 2006;12:1310-6.

23. Mahan LK, Escott-Stump S. Krause's Food, Nutrition, \& Diet Therapy. $12^{\text {th }}$ ed. St. Louis, Missouri: Elsevier; 2008.

24. Gibson RS. Principles of Nutritional Assessment. USA: OXFORD University Press; 2005.

25. Indian Council of Medical Research (ICMR). Nutrition Requirements $\&$ Recommended Dietary Allowances for Indians a Report of the Expert Group of the Indian Council of Medical Research. National Institute of Nutrition. Hyderabad, India: Indian Council of Medical Research; 2010. 
26. Khan MA, Khan MA. Nutrition in Growth \& Health. Islamabad: Planning \& Development Division Government of Pakistan; 1980.

27. Plauth M, Merli M, Kondrup J, Weimann A, Ferenci P, Müller MJ, et al. ESPEN guidelines for nutrition in liver disease and transplantation. Clin Nutr 1997; 16:43-55.

28. Harris JA, Benedict FG. A Biometric Study on Basal Metabolism in Men. Public No. 279. Washington, DC: Carnegie Institute of Washington; 1919.

29. Bakshi N, Singh K, Seth V, Jerath SJ. Impact of malnutrition on nutritional and nonnutritional factors in end stage liver disease. Asian J Clin Nutr 2017;9:77-88.

30. Bakshi N, Singh K, Soin AS. Nutrition in liver transplant recipients: Case series. Open J Clin Med Case Rep 2015;1:1-15.

31. Bakshi N, Singh K. Nutrition profile of a liver transplant recipient:
A case report. Hepatoma Res 2016;2:98-102.

32. Stickel F, Hoehn B, Schuppan D, Seitz HK. Review article: Nutritional therapy in alcoholic liver disease. Aliment Pharmacol Ther 2003;18:357-73.

33. Stickel F, Inderbitzin D, Candinas D. Role of nutrition in liver transplantation for end-stage chronic liver disease. Nutr Rev 2008;66:47-54.

34. Hasse JM. Nutritional implications of liver transplantation. Henry Ford Hosp Med J 1990;38:235-40.

35. Hasse J. Role of the dietitian in the nutrition management of adults after liver transplantation. J Am Diet Assoc 1991;91:473-6.

36. Hasse J, Strong S, Gorman MA, Liepa G. Subjective global assessment: Alternative nutrition-assessment technique for liver-transplant candidates. Nutrition 1993;9:339-43. 